\title{
Novel Route for Antibacterial Finishing of Cotton Fabric Based on Ag Loaded Cyclodextrin -PAN Copolymers
}

\author{
A.Hebeish, A.Higazy, M.AbdelHady and S.Sharaf \\ National Research Centre, Textile Division, Textile Chemistry \\ and Technology, Department of Preparation and Finishing of \\ Cellulosic Fibers, Scopus affiliation ID 60014618, 33El \\ Bohouth st.-Dokki-Giza, Cairo.
}

\begin{abstract}
LEREIN, we represent a novel route for antibacterial finishing of cotton fabric. The novelty involves preparation of cyclodextrins based copolymers which are applied along with silver nitrate to yield silver nanoparticles (AgNPs). The latter are intermediately associated with the copolymer which is distributed in the fiber-fabric structure. In a more specific sense, the present work comprises three main studies 1) Synthesis of novel finishes based on graft copolymerization of $\beta$ cyclodextrin $(\beta-C D)$ and reactive cyclodextrin (RCD) with acry lonitrile $\mathrm{AN}, 2$ ) characterization of obtained copolymers and 3) application of these copolymers along with $\mathrm{AgNO}_{3}$ to cotton fabric to ultimately create Ag NPs in the fiber-fabric structure. In the first study optimal condition of the synthesis of said copolymers were established. The second study was devoted to monitoring nitrogen content, graft yield percent and grafting efficiency percent. The third study emphasized the application of the copolymer in presence of silver nitrate which is converted to AgNPs under the copolymer dual reducing and stabilizing action. The copolymers containing AgNPs were embedded within the cotton fabric and imparted to it thermal stability along with antibacterial properties .It was also found that using RCD as a base for copolymerization with AN displays higher effects in terms of nitrogen content, graft yield, than $\beta$-CD.
\end{abstract}

Keywords: Cyclodextrins, Acrylonitrile, Silver nanoparticles and Concurrent treatment .

In recent years, there has been growing research interests in polymer modification by grafting method, which can introduce various functional groups onto polymers without altering bulk properties ${ }^{(1-3)}$. Acrylonitrile is one of the most frequently used monomer for polymer modification ${ }^{(4)}$. Mishra et al. found that the tensile strength and modulus of sisal fibers increased by grafting with $5 \%$ acrylonitrile. The barrier property against oxygen of poly ethyleneterephthalate (PET) film could be greatly improved by grafting with acrylonitrile ${ }^{(5)}$. Because of various derivatives can be obtained by the reactions of nitrile groups, inert polymers can be functionalized by grafting with acrylonitrile to import reactive nitrile groups, which allow for further chemical treatments.

Acrylonitrile is oil soluble, and traditionally the grafting of acrylonitrile is conducted in organic solvents, which is not environment friendly. Emulsion 
grafting (6). was found to be an efficient grafting method for oil-soluble monomers instead of the reaction in organic solvents

Ali et al. improved the electrical characteristics and thermal stability of polypropylene (PP) sheets via grafting with acrylonitrile ${ }^{(7)}$.In another study the subsequent chemical modification of nitrile group with phenylenediamine and glyoxal to develop a conjugated double bond chain structure within PP chains Amidoxime group derived from nitrile group can chelate some kinds of heavy metal ions such as $\mathrm{Hg}(\mathrm{II}), \mathrm{Cu}(\mathrm{II}), \mathrm{Cd}(\mathrm{II}), \mathrm{Ni}(\mathrm{II})$ and $\mathrm{UO}_{2}$ (II) ions with high efficiency ${ }^{(8)}$. Therefore, grafting of acrylonitrile on to polymers can manufacture the sorbents containing amidoxime groups, which are promising in applications of wastewater treatment and extraction of uranium from seawater ${ }^{(9,10)}$

An antibacterial dressing material was prepared by immobilizing silver (I) ions onto acrylonitrile grafted silk fibers ${ }^{(11)}$. Jewrajka et al. revealed from his study that when $\mathrm{Ag}$ ions are reduced in presence of polyacrylonitrile (PAN) solution and followed by solvent evaporation, the produced Ag-Nps undergo aggregation and precipitation. This is due to the weak electrostatic interaction between $\mathrm{CN}$ and $\mathrm{Ag}$ - Nps surface in presence of PAN solution and followed by solvent evaporation ${ }^{(12)}$

Cyclodextrins (CDs) are a family of soluble, non-toxic molecules consisting of 6,7 or $8 \mathrm{~d}$-glucopyranosyl residues (denoted as $\alpha$-, $\beta$ - and $\gamma$-CDs, respectively) linked in cyclic structure by $\beta-1,4$ glycosidic bonds. They can form inclusion complexes incorporating various molecular guests within their hollow, truncated cone shaped cavity structure, enabling them to be used as drug carriers and enzyme mimics. Host-guest interaction has been attributed to a combination of weak interactions such as van der Waals forces, hydrogen bonding and hydrophobic interactions ${ }^{(13,14)}$. Of the three cyclodextrins, $\beta-C D$, with an internal cavity diameter of $0.78 \mathrm{~nm}$, is the most widely used but is too small to entrap silver nanoparticles (AgNPs) and simply binds via chemisorptions to the nanoparticles through rim hydroxyl groups. Unmodified $\beta$-CD has been used to prepare silver and gold nanoparticles in the presence of different reducing agents such as ethanol, dimethylformamide, ethylene glycol and sodium citrate. It was also reported that $\beta-\mathrm{CD}$ enhances the antibacterial properties of $\mathrm{AgNPs}^{(15)}$.

Recent studies in our laboratories ${ }^{(16-18)}$ have involved the synthesis and characterization of two polymeric products based on, cyclodextrin and monochlorotriazinyl- $\beta$ cyclodextrin grafted with poly acrylic acid and their utilization by different method of treatments to prepare nano-silver colloidal solutions. The silver nanoparticles colloidal solution(s) was applied to cotton fabric. The innovative formulation in question results in fabrics with excellent and durable antibacterial properties.

We undertake this study with a view to synthesize novel antibacterial finishes for cotton textiles. The novelty is based on insitu perpetration of silver

Egypt. J. Chem. 59, No.5 (2016) 
nanoparticles (AgNPs)-loaded $\beta$-cyclodextrin ( $\beta$-CD-polyacrylonitrile (PAN) graft copolymer included in cotton fabric and, AgNPs loaded reactive cyclodextrin (RCD)-PAN graft copolymer within the fabric. In more specific sense, the said copolymer are independently copolymerized with AN using $\mathrm{K}_{2} \mathrm{~S}_{2} \mathrm{O}_{8}$ as initiator and the obtained copolymers along with silver nitrate $\left(\mathrm{AgNO}_{3}\right)$ are applied at $\mathrm{pH} 9$ to cotton fabric where AgNPs are created within the copolymer which is intimately associated with fabric through physical forces and /or chemical bonding particularly in case of RCD-based copolymer. Synthesis of the copolymer is carried out under different conditions and they are submitted to analysis and characterization. The insitu preparation through concurrent application of the copolymers together with formation of AgNPs to cotton fabric is emphasized as a novel technique. Antibacterial activity of the treated fabric is investigated. Tentative mechanisms for grafting, antibacterial activity and $\mathrm{Ag}$ NPs formation are elucidated.

\section{Materials and Methods}

\section{Materials}

Cotton fabric

Mill desized, scoured and bleached 100\% cotton fabric (Poplin) was supplied by Misr Spinning and Weaving Company, Mehala El- Kubra, Egypt. The fabric was further purified by washing at $100^{\circ} \mathrm{C}$ for $30 \mathrm{~min}$. in a solution containing 2 $\mathrm{g} / 1 \mathrm{Na}_{2} \mathrm{CO}_{3}, 1 \mathrm{~g} / 1$ Egyptol (non-ionic wetting agent based on ethylene oxide condensate) The fabric was then washed for several times with boiling water followed by cold water and finally dried at ambient conditions .

\section{Chemicals}

Monochlorotriaznyl $\beta$-cyclodextrin referred to here as reactive $(\beta C D)$ and (RCD) and $\beta$-cyclodextrin $(\beta-C D)$ were purchased from Wacker Chemie GMBH, Germany, Sodium hydroxide, acrylonitrile ,potassium persulphate and silver nitrate were of laboratory grade chemicals, Egyptol(non-ionic wetting agent based on ethylene oxide condensate) was of technical grade chemicals .

\section{Copolymerization procedure}

The graft polymerization was carried out in $100 \mathrm{ml}$ stopper flasks containing two of such flasks one of which contains aqueous solution of $\beta-\mathrm{CD}$ and the other contains reactive $\beta$-CD $\left(1 \mathrm{~g} / 50 \mathrm{ml} \mathrm{H}_{2} \mathrm{O}\right)$ The two flasks were stopper and placed in a thermo stated water bath for a certain period until the required temperature $\left(65^{\circ} \mathrm{C}\right)$ was reached. At this end potassium persulfate $0.006 \mathrm{~mol} / \mathrm{L}$, was added into each flask followed by drop wise addition of AN $0.9 \mathrm{~mol} / \mathrm{L}$. The flasks contents were shaken occasionally during the first $60 \mathrm{~min}$ polymerization time (60 $\mathrm{min}$ ). After that the mixture was continuously stirred for $15 \mathrm{~min}$. at room temperature, and the solid mixture was washed with distilled water till $\mathrm{pH} 7$, then washed by alcohol and finally dried at ambient condition. The product contained graft copolymer and homopolymer in order to remove the PAN homopolymer, the crude products were stirred at room temperature with dimethylformamide 
(DMF) for several times, the pure $\beta-\mathrm{CD}-\mathrm{g}-\mathrm{PAN}$ and $\mathrm{RCD}-\mathrm{g}-\mathrm{PAN}$ were thoroughly washed with alcohol then dried at ambient conditions.

\section{Cotton fabric treatment}

Cotton treatment in our case study is depend on fixation of $\beta-\mathrm{CD}-\mathrm{g}-\mathrm{PAN}$ as well as RCD -g-PAN by two different method of treatment according to fixation method commonly used for each polymer separately This step is done concurrent with the step of synthes is of Ag nanoparticles.

a) Synthesis of Ag nanoparticles on cotton fabric using $\beta$-CD -g-PAN

$1 \mathrm{gm}$ of $\beta$-CD -g-PAN was dissolved using material to liquor ratio $1: 30$. 5\% glutraldehyde as a crosslinking agent and $1 \%$ magnesium chloride as a catalyst were added to the treatment bath .The $\mathrm{pH}$ of the bath was adjusted to 9 by using $0.1 \mathrm{~N} \mathrm{NaOH}$, the contents of the bath were homogenized using homogenizer for 5 min, fabric was immersed in bath followed by a drop wise addition of $\mathrm{AgNO}_{3}$ solution $(0.0003 \mathrm{~mol}))$ then squeezed to a wet pick-up of about $100 \%$ by padder. The cotton fabric was dried at $80^{\circ} \mathrm{C}$ for $5 \mathrm{~min}$ and then cured at $120^{\circ} \mathrm{C}$ for $3 \mathrm{~min}$. Finally the treated fabric was washed with hot water and dried at ambient conditions.

b) Synthesis of Ag nanoparticles on cotton fabric using R -CD -g-PAN

$1 \mathrm{gm}$ of RCD -g-PAN, was dissolved using material to liquor ratio 1:30.. The $\mathrm{pH}$ of the bath was adjusted to 9 by using $0.1 \mathrm{~N} \mathrm{NaOH}$, the content of the bath were homogenized using homogenizer for $5 \mathrm{~min}$, then $0.5 \mathrm{gm}$ fabric was immersed in the treatment bath followed by a drop wise addition of $\mathrm{AgNO}_{3}$ solution $(0.0003 \mathrm{~mol})$ ) . The reaction temperature was raised to $70^{\circ} \mathrm{C}$ for $60 \mathrm{~min}$. Finally the treated fabric was washed with hot water and dried at ambient conditions.

\section{Analysis and characterization}

\section{Analysis}

- Percent graft yield (GY \%) and graft efficiency (GE \%)

The extent of polymerization expressed as percent graft yield (GY\%) and the percent graft efficiency (GE \%) were calculated according to the following equations:

$\mathrm{GY} \%=\left(\mathrm{W}_{2}-\mathrm{W}_{1} / \mathrm{W}_{1}\right) \times 100$

$\mathrm{GE} \%=\left(\mathrm{W}_{2}-\mathrm{W}_{1} / \mathrm{W}_{\mathrm{m}}\right) \times 100$

where $\mathrm{W}_{2}$ and $\mathrm{W}_{1}$ and $\mathrm{W}_{\mathrm{m}}$ donate the weight of the $\mathrm{B}-\mathrm{CD}$-g- PAN or RCD-gPAN , the weight of original $B C D$ or RCD and weight of the monomer used, respectively.

\section{- Nitrogen content}

The nitrogen percent ( $\mathrm{N} \%$ ) of the obtained graft copolymers was determined and calculated according to a method described elsewhere ${ }^{(19)}$ 


\section{Characterization}

- Fourier Transform Infrared Spectroscopy (FTIR) was recorded on a Nicolet-20 DXB-Infrared spectrophotometer using the potassium bromide disk technique in the range of $4000-400 \mathrm{~cm}^{-1}$. The disk was prepared from grinded samples (2 mg) and $\mathrm{KBr}(45 \mathrm{mg})$ using $400 \mathrm{~kg} / \mathrm{cm}$ pressure for 10 $\min$.

- Scanning Electron Microscope (SEM) was used to detect the changes in the surface characteristics of the cotton fabrics due to treatment with $\mathrm{BCD}$ g- PAN or RCD-g-PAN. Surface morphology of prepared cotton samples were examined on aJEAOL JXA-840 scanning electron microscope (SEM). The prepared samples were coated with a thin layer of palladium gold alloy after mounting on a double sided carbon tape.

- Energy dispersive X-ray (EDS) was employed to analyze the surface elemental compositions using a scanning electron microscope (JEOL,JXA840A Electron Probe Micro analyzer-Japan) equipped with an energy dispersive X-ray system(EDX) (INCAX- 145 Sight-England).

- Thermo Gravimetric Analysis TGA measurements were carried out using 8-10 $\mathrm{mg}$ of the samples at a heating rate of $283 \mathrm{~K} \cdot \mathrm{min}^{-1}$ in an $\mathrm{N}_{2}$ atmosphere using a TGA/SDT Q600 analyzer. The TGA was conducted with the compounds placed in a high-quality nitrogen $(99.5 \%$ nitrogen, $0.5 \%$ oxygen content) atmosphere with a flow rate of $20 \mathrm{ml} \mathrm{min}^{-1}$, to avoid unwanted oxidation. Each sample was scanned over a temperature range from 298 to $1073 \mathrm{~K}$.

- Antibacterial Activity of the treated samples against Staphylococcus aureus $(\mathrm{G}+\mathrm{ve})$ bacteria and Escherichia coli (G-ve) bacteria were determined using agar plate method. The plates were incubated at $37{ }^{\circ} \mathrm{C}$ for $24 \mathrm{hr}$, a growth free zone of inhibition around the fabric appears as the antibacterial agent migrates from the fabric onto the agar, and diffused outward. Diameter of inhibition zones was determined according to AATCC test method 100-199.

\section{Results and Discussion}

\section{Tentative mechanism}

In an aqueous solution containing $\beta C D, \mathrm{~K}_{2} \mathrm{~S}_{2} \mathrm{O}_{8}$, acrylonitrile (AN), a typical free radical polymerization reaction operates. The mechanism involved in the system proceeds as per several reactions, notably graft copolymerization and homopolymerization as shown by Scheme 1. Virtually all free radical chain reactions require a separate initiation step in which a radical species is generated in the reaction mixture. Decomposition of $\mathrm{K}_{2} \mathrm{~S}_{2} \mathrm{O}_{8}$ gives rise to $\mathrm{SO}_{4}^{--}$which can undergo a series of reactions leading ultimately to $\mathrm{HO}^{*}$ (hydroxyl free radical). The $\mathrm{SO}_{4}{ }^{-}$and/or $\mathrm{HO}^{*}$ abstract hydrogen atom from $\beta-\mathrm{CD}$, molecule to yield $\beta$ $\mathrm{CD}$, free radical to which an AN molecules is added forms the initiation step of 
graft copolymerization Subsequent addition of AN molecules to the so initiated chain forms the propagation step. Termination of growing grafted chains occurs via coupling of two graft radicals or through disproportion. Concurrently with grafting, propagation and termination of homopolymer occur.

Initiation

$$
\begin{array}{ll}
\mathrm{S}_{2} \mathrm{O}_{8}{ }^{-2} \longrightarrow 2 \mathrm{SO}_{4}{ }^{-} & 1 \\
\mathrm{SO}_{4}{ }^{-}+\mathrm{H}_{2} \mathrm{O} \longrightarrow \mathrm{HSO}_{4}{ }^{-}+\mathrm{HO} & 2 \\
\mathrm{SO}_{4}{ }^{-}+\beta \mathrm{CD}-\mathrm{OH} \longrightarrow & \\
\mathrm{HO}+ & \\
& \\
\beta \mathrm{CD}-\mathrm{CD}-\mathrm{OH}+\mathrm{CH}_{2}=\mathrm{CHCN} \longrightarrow & +\mathrm{HSO}_{4}{ }^{-}
\end{array}
$$

Propagation of grafting

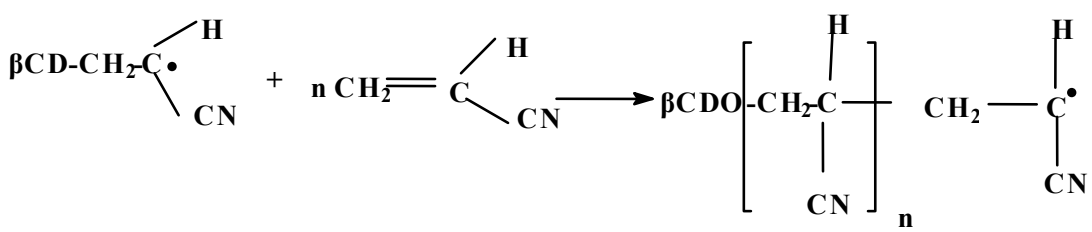


Termination of grafting, for example, by coupling

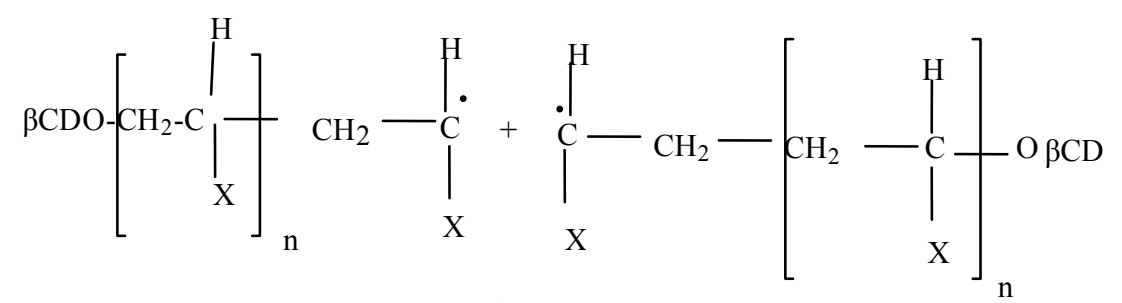<smiles>[3H][V]</smiles>

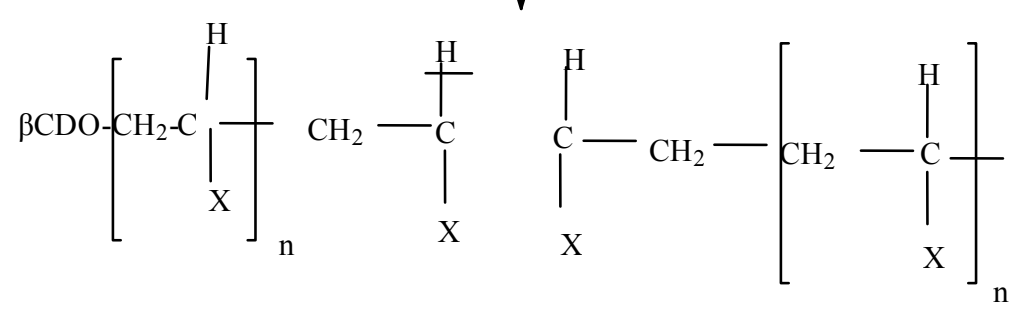

Initiation of homopolymerization

$$
\begin{aligned}
& \mathrm{CH} 2=\mathrm{C}_{\mathrm{CN}}^{\mathrm{H}}+\mathrm{OH} \longrightarrow \mathrm{HO}-\mathrm{CH}_{2}-\left.\mathrm{C}\right|_{\mathrm{CN}} ^{\mathrm{H}} \\
& \mathrm{CH}_{2}=\mathrm{C}_{\mathrm{CN}}^{\mathrm{H}}+\mathrm{SO}_{4} \cdot-\longrightarrow \mathrm{SO}_{4}-\mathrm{CH}_{2}-\left.\right|_{\mathrm{CN}} ^{\mathrm{H}} \cdot
\end{aligned}
$$

Propagation of homopolymerization

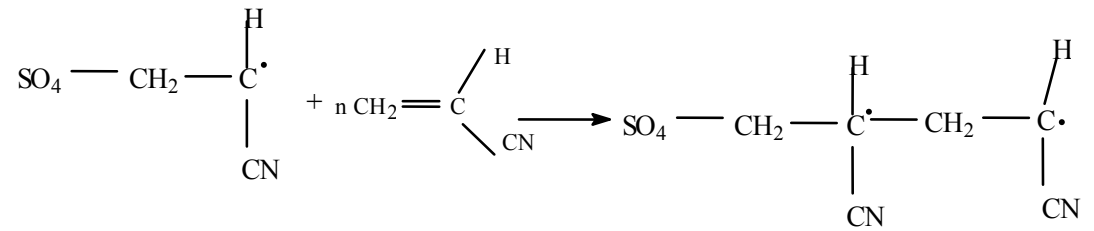


Synthesis of $\beta C D$ and RCD-PAN graft copolymers

Synthes is of $\beta$-CD-PAN and RCD-PAN graft copolymers was conducted under different conditions including time of polymerization as well as concentration of monomer (AN) and initiator concentration (potassium persulphate). This was done to discover the most appropriate conditions for synthesis of the copolymers in question.

Time of the polymerization Reaction

Figure $1(\mathrm{a}, \mathrm{b})$ shows the effect of polymerization time on the percent graft yield $(\mathrm{GY} \%)$ and graft efficiency (GE\%), when acrylonitrile (AN) was polymerized independently onto $\beta-\mathrm{CD}$ and $\mathrm{RCD}$. The polymerization reaction was carried out at $65 \mathrm{C}$ using potassium persulphate as detailed in the experimental section. Care was taken to keep the polymerization system in a tightly closed vessel to avoid evaporation of acrylonitrile $\left(78^{\circ} \mathrm{C}-79^{\circ} \mathrm{C}\right)$. It is seen (Figure 1a and b) that the polymerization reaction exhibit induction periods of one hour in case of $\beta-C D$ and 20 minutes in case of RCD graft polymerization to start with AN, After the induction period the polymerization reaction with both $\beta-C D$ and $R C D$ proceeds very fast to attain maximum then decrease sharply. It is certain, however, that RCD is more susceptible towards grafting than $\beta-\mathrm{CD}$ reflecting the favorable derivatization effect of $\beta-\mathrm{CD}$ on its amenability to grafting.

Decrement in the extent and rate of grafting of $A N$ onto $\beta-C D$ and RCD could be ascribed to depletion in both monomer and initiator concentration as the graft polymerization reaction proceeds. It is also likely that larger amount of homopolymer formation on the charge of grafting occurs during later stages of polymerization thus decreasing the magnitude of grafting formation .In combination with this is the possibility of modification of $\beta-\mathrm{CD}$ and RCD particularly, during the latest stage of polymerization. Such modification seems to have an adverse effect on diffusion and adsorption of monomer and initiator on the backbone of $\beta-\mathrm{CD}$ and $\mathrm{RCD}$ as parent substrate for grafting.

\section{Initiator concentration}

Figure $2(a, b)$ shows the effect of potassium persulphate concentration on GY\% and GE\% of when AN was copolymerized with $\beta C D$ and (RCD). Results disclose that no grafting occurs when potassium persulphate concentration was less than 0.004 mole $/ 1$ which an concentration above (up to 0.006 mole/ $\mathrm{L}$ ) cause remarkable increase in the G.Y\% and G.E\% irrespective of the nature of cyclodextrin used, but with certainly that values of G.Y.\% and G.E\% are higher with RCD than $\beta C D$ as discussed above .Using potassium persulphate concentration higher than 0006 mole/ 1 is accompanied by a decrement in the G.Y.\% and G.E.\%.

Egypt. J. Chem. 59, No.5 (2016) 


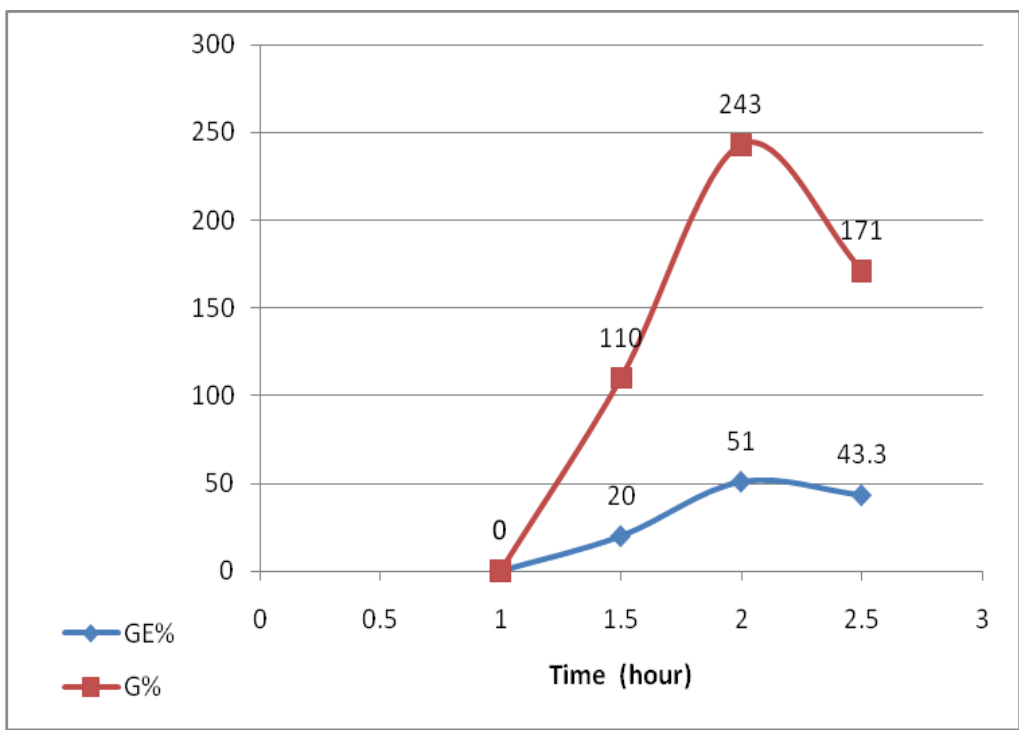

Fig. 1a. Effect of time on grafting of betacyclodextrin with acrylonitrile.

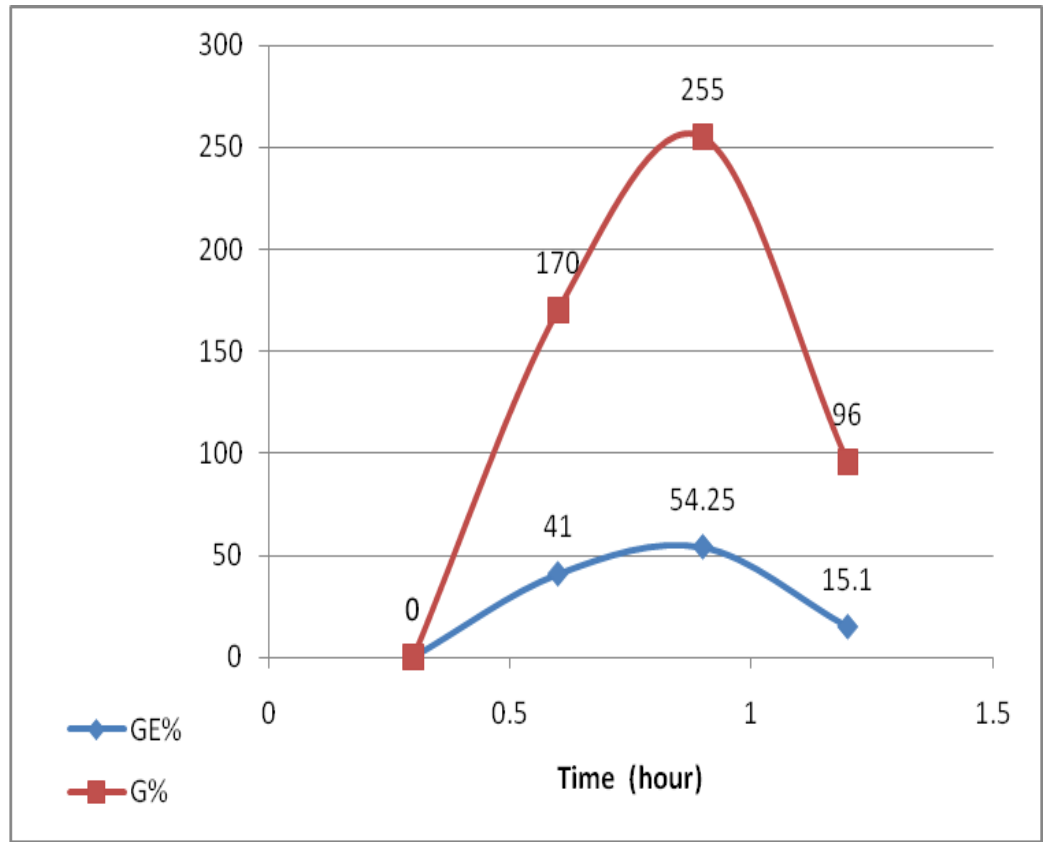

Fig. 1b. Effect of time on grafting of reactive cyclodextrin with acrylonitrile.

Egypt. J. Chem. 59, No.5 (2016) 


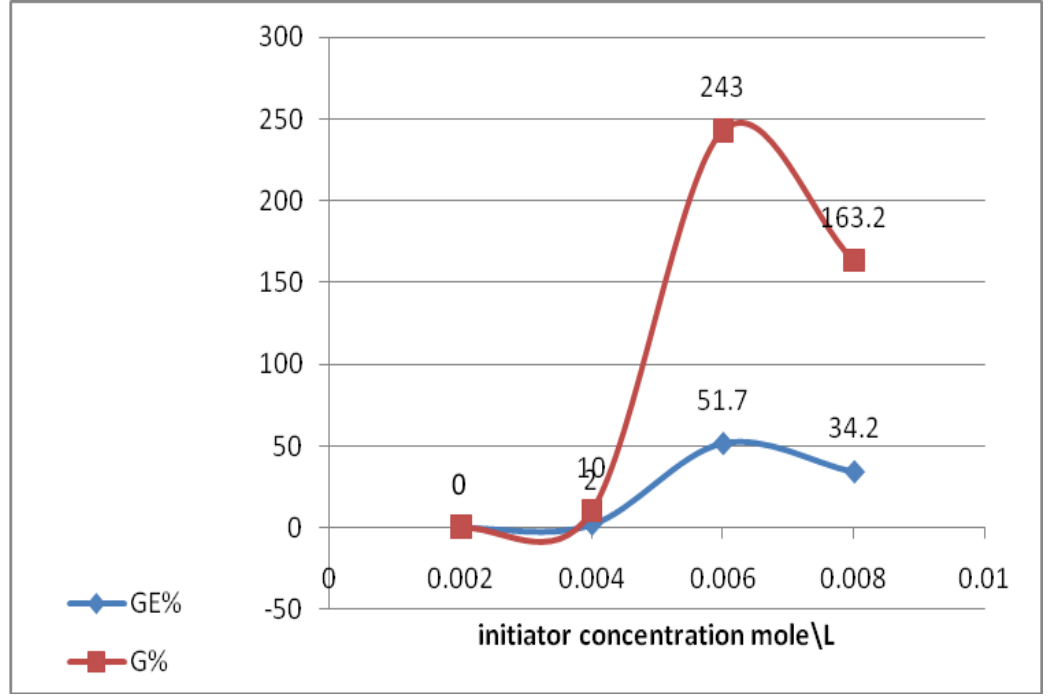

(a)

Fig. 2a. Effect of initiator concentration on grafting of beta cyclodextrin with acrylonitrile.

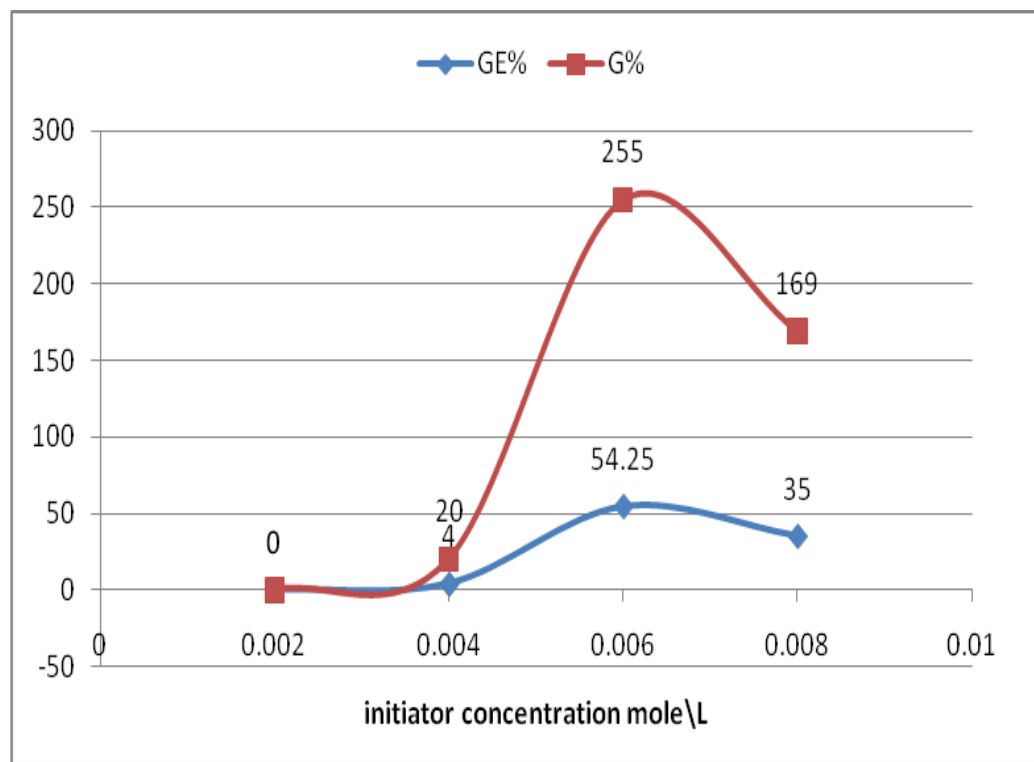

(b)

Fig. 2b. Effect of initiator concentration on grafting of reactive cyclodextrin with acrylonitrile.

Egypt. J. Chem. 59, No.5 (2016) 
Enhancement in G.Y. \% and G.E. \% by increasing potassium persulphate concentration up to $0.006 \mathrm{~mole} / \mathrm{L}$ could be interpreted in terms of creation of more active species which contribute largely in initiation of polymerization .On the other hand, higher potassium persuphate concentration seems to result in termination of the polymerization reaction. It is logical that the ultimate effect of abundance of active species cause faster rate of termination, thereby giving rise to lower G.Y.\% and G.E.\%.

\section{Acrylonitrile concentration}

Figure 3(a,b) shows the effect of AN monomer concentration on the G.Y. $\%$ and $\mathrm{G} . \mathrm{E} \%$ when $\beta-\mathrm{CD}$ and $\mathrm{RCD}$ were independently polymerized with $\mathrm{AN}$. As is evident no grafting occurs when $\mathrm{AN}$ concentration of 0.3 mole/L (based on weight of substrate) was used. Increasing monomer concentration from 0.3 mole/L to 0.9 mole/L is accompanied by a progressive increment in percent $\mathrm{GY} \%$ and $\mathrm{GE} \%$, then levels off with further increase in $\mathrm{AN}$ concentration. The progressive increment in $\mathrm{GY} \%$ and $\mathrm{GE} \%$ by increasing $\mathrm{AN}$ concentration is a direct consequence of great availability of monomer molecules in the vicinity of cyclodextrin molecules at higher AN concentration. On the other hand, leveling off of grafting could be associated with a ) shortage of active sites on the CD molecules at higher AN concentration due to progressive grafting and (b) the large PAN formation seems to make the diffusion of AN monomer or modifying the $\mathrm{CD}$ backbone in such a way that it becomes no more accessible for grafting.

Analysis and characterization of the synthesized copolymer

Analysis of $\beta C D$ and $\beta C D-P A N$ graft copolymer

Results of nitrogen content, graft yield and graft efficiency obtained when blank $\beta-C D$ and RCD were grafted with AN to yield $\beta-C D-g-P A N$ and RCD -gPAN are rather interesting. The two cyclodextrin are substantially amenable to grafting with $\mathrm{AN}$ under the conditions used. However, RCD acquires higher graft content than $\beta-\mathrm{CD}$ as evidenced by the results of $\mathrm{N} \%$, GY\% and GE\%. This means that derivatization of $\beta-\mathrm{CD}$ via introduction monochlorotriazinyl moieties enhances the reactivity of $\beta C D$ towards grafting with acrylonitrile. That is, the $\beta C D$ derivative (RCD) is more susceptible to grafting than $\beta C D$ (Table 1).

TABLE 1. Nitrogen content, GY \% GE \% and of the synthesized graft copolymers.

\begin{tabular}{cccc}
\hline Substrate & N\% & $\begin{array}{c}\text { Graft yield } \\
(\mathbf{\%})\end{array}$ & $\begin{array}{c}\text { Graft efficiency } \\
\text { (\%) }\end{array}$ \\
\hline BCD-g- PAN & 16.87 & 71.5 & 37.63 \\
\hline RCD-g-PAN & 19.68 & 77.5 & 40.78 \\
\hline
\end{tabular}




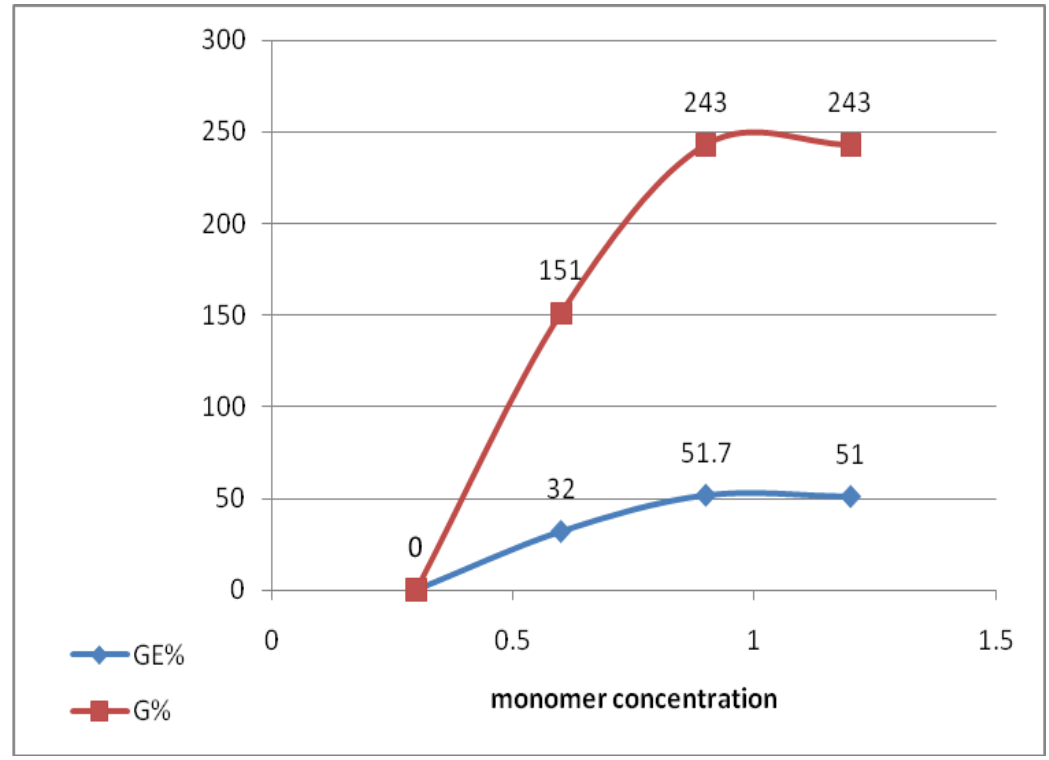

Fig. 3a. Effect of monomer concentration on grafting of betacyclodextrin with acrylonitrile.

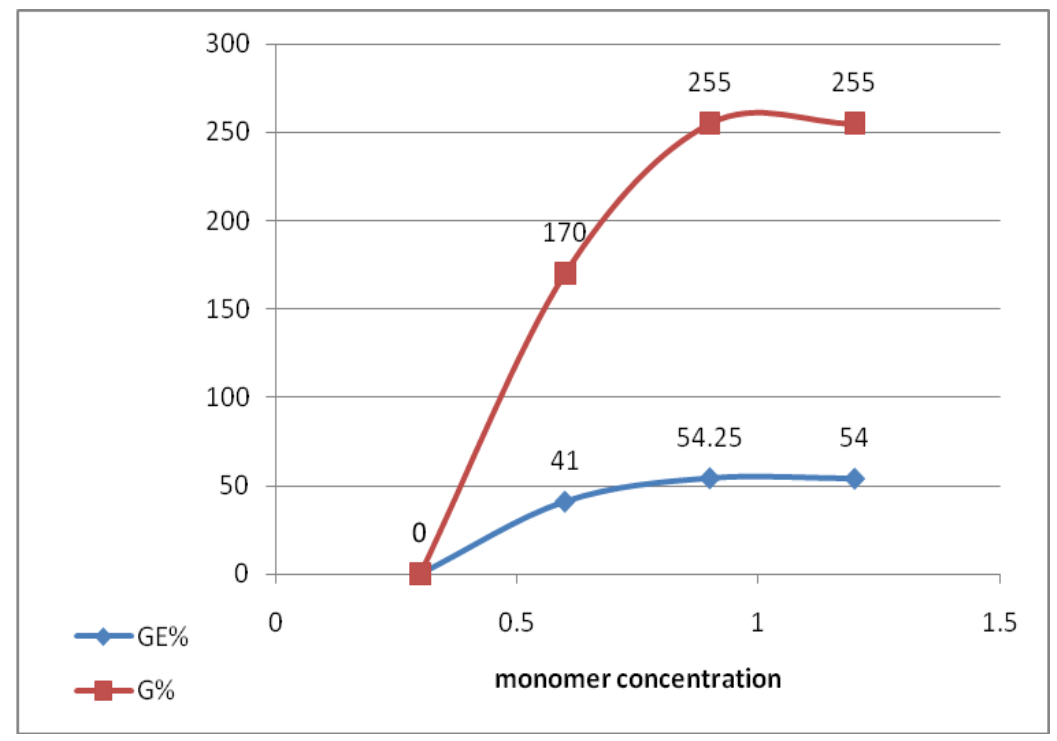

Fig. 3b. Effect of monomer concentration on grafting of reactive cyclodextrin with acrylonitrile.

Egypt. J. Chem. 59, No.5 (2016) 
FTIR of $\beta C D, R C D$, and their PAN graft copolymer

Structural changes of $B C D, R C D$ and their graft copolymers with PAN were characterized by FTIR in Figure 4. ( Fig. 4 a) illustrates the IR spectra of blank $\beta$ $\mathrm{CD}$ and its corresponding copolymer $\beta-\mathrm{CD}-\mathrm{g}-\mathrm{PAN}$ while Fig $4 \mathrm{~b}$ represents blank RCD and its corresponding copolymer RCD-g-PAN. In FTIR spectra for both blank $\beta-C D$ and blank RCD, the $\mathrm{OH}$ stretching absorption displays a typical broad peak $3371 \mathrm{~cm}^{-1}$. The peak from $2932 \mathrm{~cm}^{-1}$ to $2119 \mathrm{~cm}^{-1}$ represents the $\mathrm{CH}_{2}$ groups. Although it has $\mathrm{CH} 2$ groups in their structure, the peaks are corresponding to the asymmetric stretching modes. The FTIR of $\beta-C D-g-$ PAN and RCD-g-PAN, the Sharp peak observed at $2246 \mathrm{~cm}^{-1}$ appears in spectra were assigned to the stretching absorption of $-\mathrm{CN}$, which prove the successful graft copolymerization of $\mathrm{BCD}, \mathrm{RCD}$ and $\mathrm{AN}^{(19)}$.

Application of the newly synthesized cyclodextrin copolymers to cotton fabric

Cotton fabric was treated with aqueous solution containing the cyclodextrin copolymers under investigation, cross linking agent (glutraldehyde), catalyst (magnesium chloride) and silver nitrate $\left(\mathrm{Ag} \mathrm{NO}_{3}\right)$ at $\mathrm{PH} 9$; keeping the sequence of ingredients addition as described in the experimental section. During the treatment the copolymer plays a dual role, (i) it acts as a reducing agent to convert $\mathrm{Ag}^{+}$to $\mathrm{Ag}^{\circ}$ and its clusters (silver nanoparticles $\mathrm{Ag} \mathrm{NPs}$ ) and (ii) it acts as a stabilizing agent for $\operatorname{AgNPs}^{(20)}$.The output is a cotton fabric bearing chemically attached cyclodextrin moiety, loaded with AgNPs in case of RCDPAN graft copolymer as well as in case of CD-PAN graft copolymer.

\section{SEM Morphological examination}

Figure 5 ( $a, b, c, d)$ shows the SEM morphology $\beta-C D$ and RCD as well as their copolymers namely $\mathrm{B}-\mathrm{CD}-\mathrm{g}-\mathrm{PAN}$ and $\mathrm{RCD}-\mathrm{g}$ - PAN respectively. It is seen that shaped particles are observed with the unmodified cyclodextrins (a, b). 'The contrary, these shaped particles disappear after copolymerization and SEM images reveal compact structure. This indicates that copolymerization of BCD and RCD with PAN destroys their particulate nature.

SEM images of fabric substrates containing BCD copolymer loaded with Ag NPs and RCD copolymer loaded with AgNPs are shown in Figure $6(a, b)$, respectively. As is evident, AgNPs in cotton bearing either of the copolymers in question are formed within the matrix of the chemically attached cyclodextrin copolymer which in turn, is distributed on the surface of the fabric. The cyclodextrin copolymers are nominated in Figure 6 as : (a) cotton fabric treated with BCD-g-PAN loaded with AgNPs and (b) cotton fabric treated with RCD-GPAN loaded with AgNPs(c). 

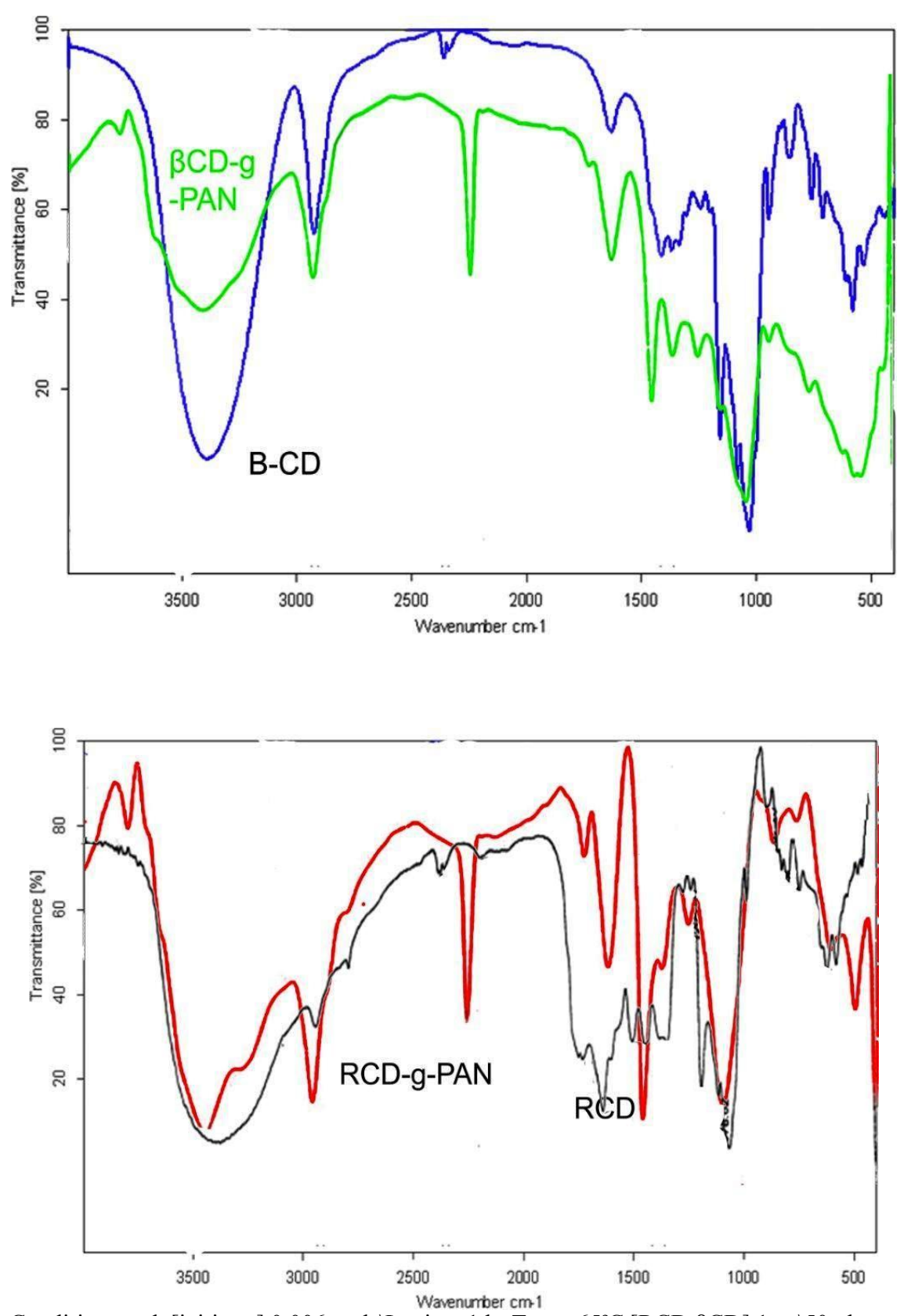

Condition used: [initiator], 0.006 mole $\backslash$; time $1 \mathrm{hr}$ Temp $.65^{\circ} \mathrm{C},[\mathrm{RCD}, \beta \mathrm{CD}], 1 \mathrm{gm} \backslash 50 \mathrm{ml}$

Fig. 4 . FTIR of BCD-,R CD and their PAN graft copolymers. 


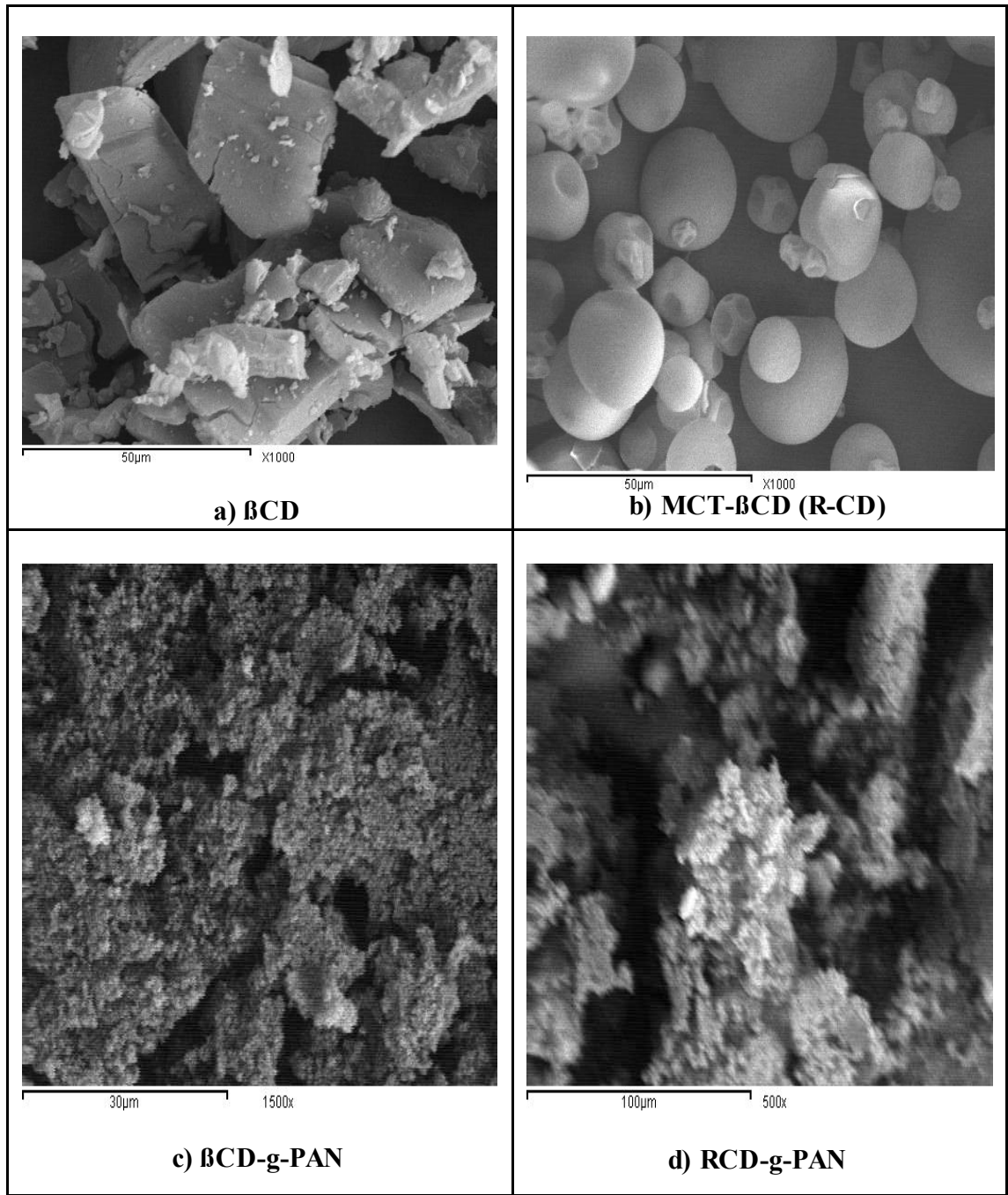

Fig. 5. (a,b,c,d). SEM images of $B C D$, RCD before and after being graft copolymerized with PAN.

\section{Antibacterial activity}

Microbiological studies were performed to investigate the antibacterial activity of the new materials against microorganisms Escherichia coli (ATCC25922) and Staphylococcus aurous (ATCC -6538) using the agar plate method. Table 2 shows the antibacterial activity expressed as inhibition zone diameter $(\mathrm{mm} / 1 \mathrm{~cm})$ of the cotton fabric containing (ß-CD-g- PAN), (RCD-g-PAN), Ag loaded $B-C D-g-P A N$ and, Ag loaded (RCD-g-PAN). The untreated cotton fabric was also subjected to the same agar plate method. Nitrogen contents of the aforementioned substrates were also determined.

Egypt. J. Chem. 59, No.5 (2016) 

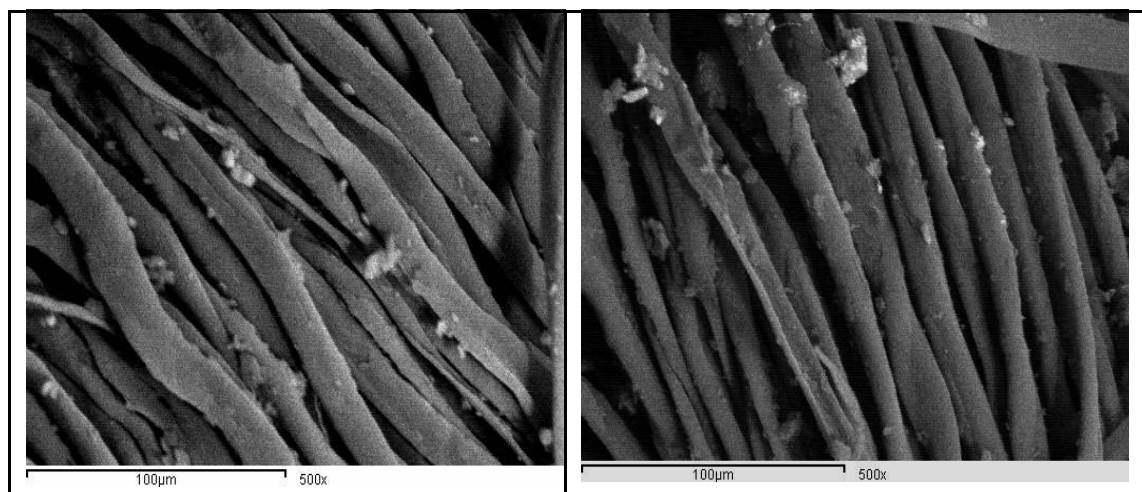

a) cotton fabric treated with BCD-gPAN loaded AgNPs.

b) cotton fabric treated with RCD-gPAN loaded AgNPs

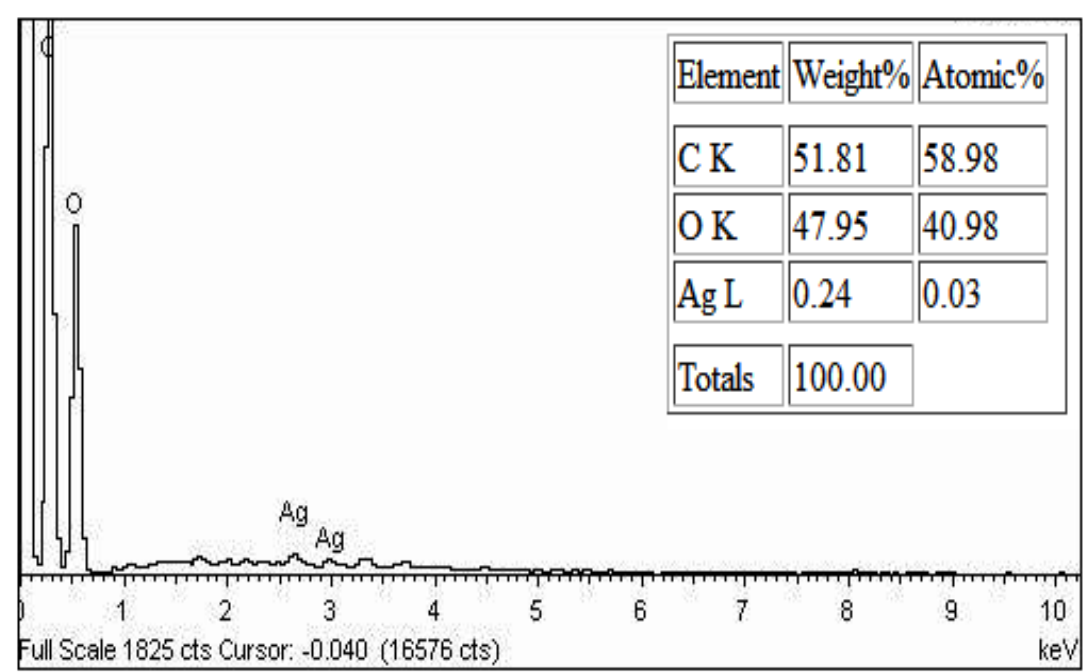

c). EDS of Ag nanoparticles embedded in the reactive betacyclodextrin -PAN graft copolymer.

Fig. 6. SEM of treated cotton fabric where a) cotton fabric treated with BCD-g-PAN loaded AgNPs b) cotton fabric treated with RCD-g-PAN loaded AgNPs \& c) EDS of AgNPs embedded in RCD-g-PAN. 
It is seen (Table 2) that the antibacterial activity of the cotton fabric containing Ag-loaded (RCD-g- PAN) displays greater antibacterial activity than the cotton fabric containing Ag-loaded (BCD -g-PAN) as shown by the inhibition zone diameter. On the other hand cotton containing $\beta-C D-g-P A N$ and RCD-gPAN show no inhibition zone. The same holds true for the untreated cotton fabric. This is probably due to the mechanism of the antibacterial action of the said copolymers containing silver nanoparticles. The silver nanoparticles cause disruption in the bacterial membrane by releasing the silver ions from the copolymer (Figure 7). The $\mathrm{Ag}^{+}$ions form insoluble compounds with sulphydryls groups in the cellular wall of the microorganism that are responsible for the inhibition halo in the seeded culture media. The antibacterial activity is confirmed by the presence of an inhibitory halo of the bacterial growth. It is proposed that intimate contact between AgNPs and organisms may enhance the transfer of $\mathrm{Ag}$ ions to the bacterial cell, whilst bacterial degradation of the $B-C D$ saccharide promotes the release of silver ions. Such interactions as shown in Figure 7 have been described as Trojan-horse mechanisms and have been reported in the literature ${ }^{(21)}$.

TABLE 2. The antibacterial activity and nitrogen percent of cotton fabric before and after treatment with Ag loaded with $\beta C D$-PAN or Ag loaded RCD-PAN copolymer.

\begin{tabular}{llcc}
\hline \multicolumn{1}{c}{ S ample } & \multicolumn{2}{c}{$\begin{array}{c}\text { Inhibition zone } \\
(\mathbf{m m} / \mathbf{1 c m} \text { sample })\end{array}$} & $\begin{array}{c}\text { Nitrogen content } \\
(\mathbf{\%})\end{array}$ \\
\cline { 2 - 3 } & $\begin{array}{c}\text { Escherichi } \\
\text { a coli } \\
(\boldsymbol{G}-)\end{array}$ & $\begin{array}{c}\text { Staphylococcus } \\
\text { aureus }(\boldsymbol{G}+)\end{array}$ & \\
\hline $\begin{array}{l}\text { Cotton /Ag loaded RCD-g- } \\
\text { PAN }\end{array}$ & 17 & 18 & 0.65 \\
\hline $\begin{array}{l}\text { Cotton containing Ag loaded } \\
\text { BCD-g- PAN }\end{array}$ & 15 & 15 & 0.40 \\
\hline $\begin{array}{l}\text { Cotton fabric containing } \\
\text { RCD-g- PAN }\end{array}$ & zero & zero & \\
\hline $\begin{array}{l}\text { Cotton containing BCD- -g- } \\
\text { PAN }\end{array}$ & zero & zero & 0.75 \\
\hline Untreated cotton & zero & zero & zero \\
\hline
\end{tabular}

Figure 8 depicts the nitrogen percent of the aforementioned treated cotton fabrics. These results are represented in Table 2. As is evident, fabric containing RCD-g- PAN exhibits the highest percent nitrogen and accordingly the treated fabrics follow the order: cotton containing RCD-g-PAN $>$ Ag-loaded ( RCD-gPAN) $>$ Ag-loaded $(\beta-C D-g-P A N)$. 


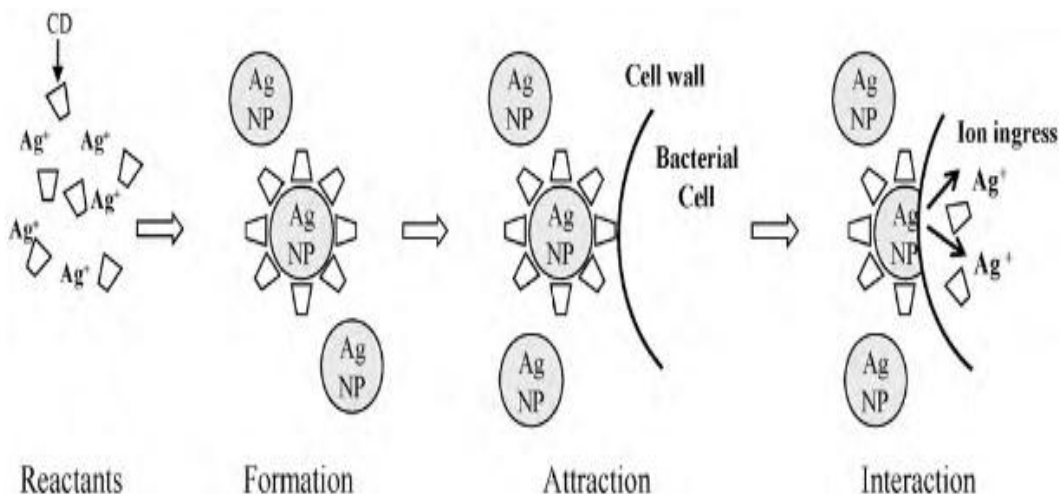

Fig. 7. Proposed bacterial interaction with $\beta$-cyclodextrin capped silver nanoparticles (Ag NPs).

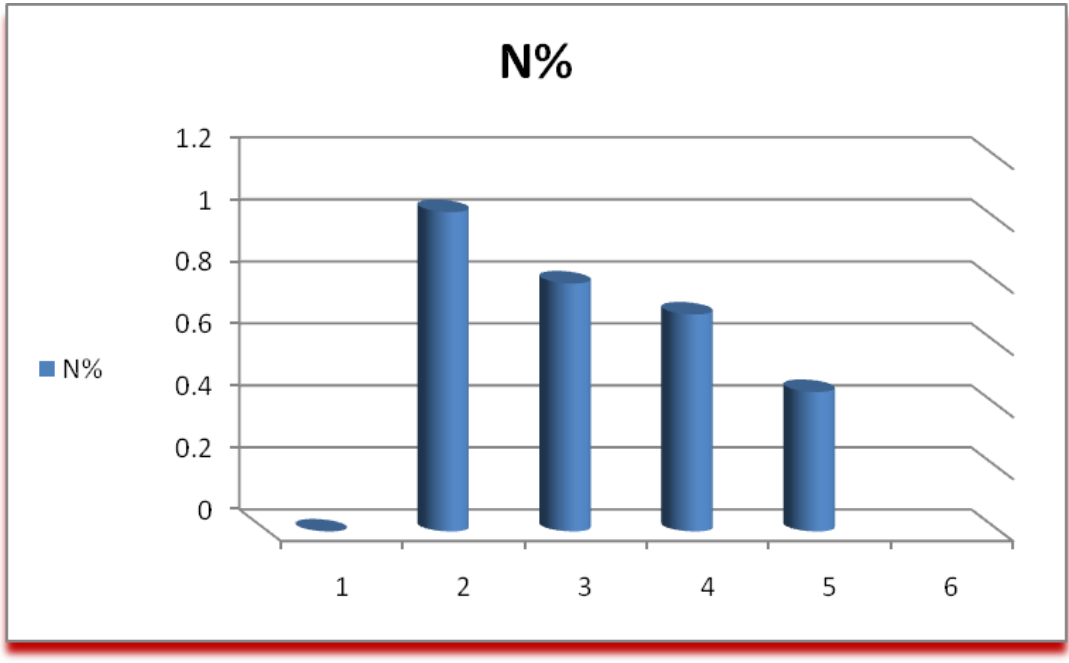

Fig.8. Nitrogen percent of treated cotton fabric, where 1) blank cotton , 2, 3) Cotton / RCD-g- PAN \& Cotton / BCD-g-PAN and 4, 5) Cotton /Ag loaded RCD-g- PAN \& Cotton /Ag loaded BCD-g-PAN.

Thermal degradation of cotton fabric containing RCD-g-PAN before and after loading with Ag NPs

Figure $9(a, b, c)$ shows analysis of (TGA) of the uncoated cotton fabric, cotton fabric containing RCD-g-PAN and cotton fabric containing Ag loaded RCD-gPAN. The TGA was carried out in nitrogen up to $600{ }^{\circ} \mathrm{C}$; the figure reveals a common profile consisting of three stages :

Egypt. J. Chem. 59, No.5 (2016) 
1. The first stage, below $100{ }^{\circ} \mathrm{C}$, is due to loss of absorbed water and water of crystallization $^{(22)}$.

2. The second stage develops in a temperature range $250-400^{\circ} \mathrm{C}$, which is associated with a weight loss of $75 \%$ in case of untreated cotton fabric, and $55 \%$ for both cotton containing RCD-g-PAN and cotton fabric containing Ag loaded RCD-g-PAN with the formation of residue (char) as seen Figure $10(a, b, c)$.

3. The third stage $\left(300-500^{\circ} \mathrm{C}\right)$ shows slow thermal degradation of the char. The degradation temperature of the first stage is reported, in decreasing order with the relative weight loss $(\Delta \mathrm{W} 1)$. It can be seen that there is a noticeable effect of the structure of the cyclodextrins on their thermal stability. The char yield (second stage) seems to increase when the thermal stability decreases. The thermal stability of the obtained chars was evaluated according to their weight to $400-600{ }^{\circ} \mathrm{C}$ in case of untreated cotton fabric and at $300-500^{\circ} \mathrm{C}$ for both cotton containing RCD-g-PAN and cotton fabric containing Ag loaded RCDg-PAN, and also to the decrease of weight to which they are subjected from $300-600^{\circ} \mathrm{C}(\Delta \mathrm{W} 2)$ as shown in Figure $10(\mathrm{a}, \mathrm{b}, \mathrm{c})$.

It is seen Figure ( $9 \mathrm{c}$ ) that the presence of silver nanoparticles in Ag loaded RCD-g-PAN with a concentration 0.24 (weight percent) as shown in EDS analysis (Figure b), has no effect on the thermal degradation of the copolymer

\section{Conclusion}

Conditions were established for synthesis of $\beta$ and reactive - cyclodextrin PAN graft copolymers. After being submitted to analysis and characterization, the copolymers were applied to cotton fabric along with silver nitrate $\left(\mathrm{AgNO}_{3}\right)$ to create a novel route for preparation of cotton fabric which displayed excellent antibacterial properties due to insitu formation of silver nanoparticles (AgNPs) via conversion of silver nitrate. The BCD-PAN copolymer or RCD -PAN copolymer performs dual action :A) as reducing agent thereby converting $\mathrm{Ag}^{+}$ion into $\mathrm{Ag}^{\mathrm{o}}$ which forms cluster of $\mathrm{AgNPs}$ and $\mathrm{b}$ ) as stabilizing agent for $\mathrm{AgNPs}$ by virtue of the polymeric nature of the copolymer. 

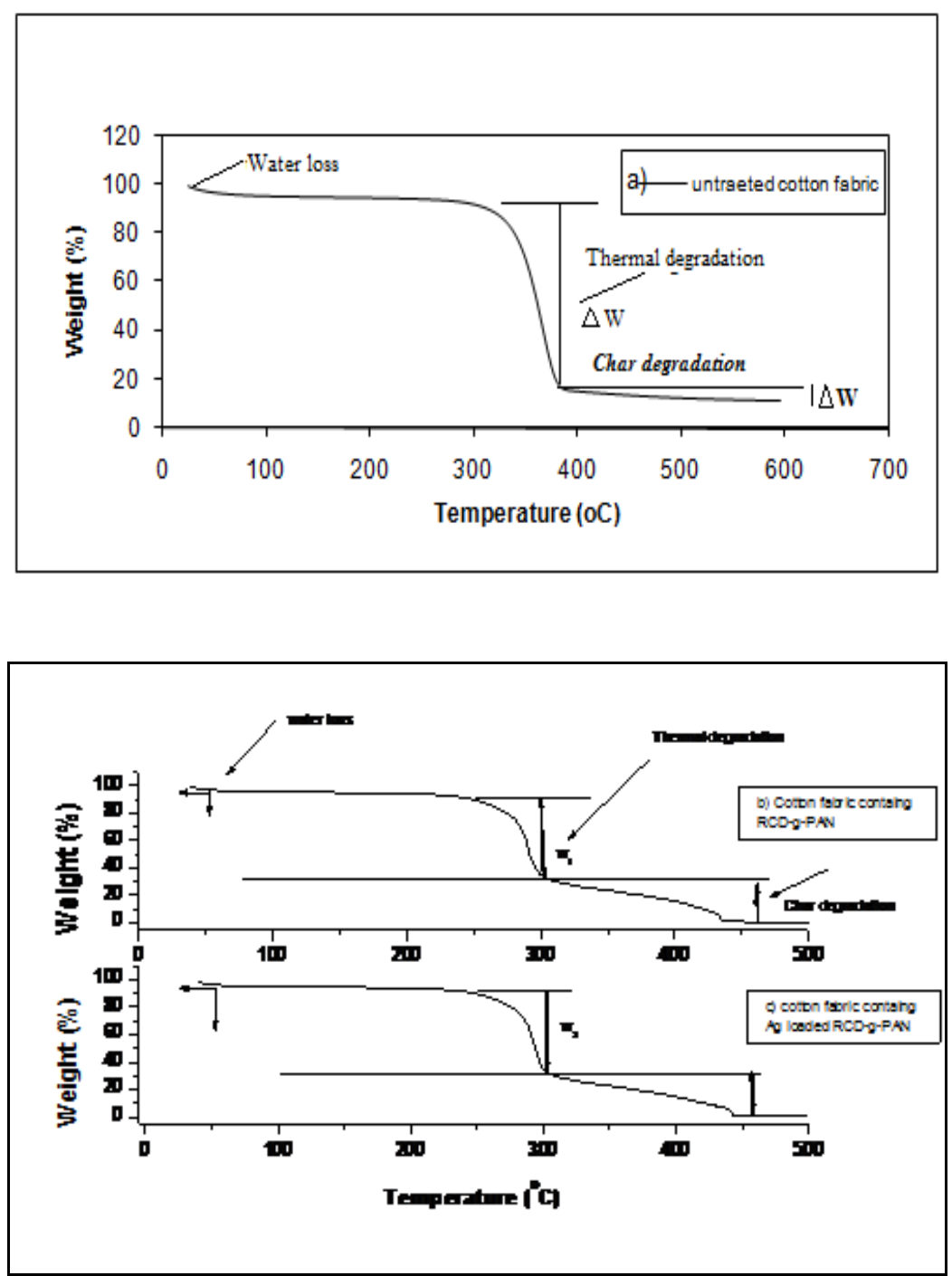

Fig. 9 (a,b,c) . Typical TGA curves of uncoated cotton fabric, cotton fabric containing RCD-g-PAN and cotton fabric containing Ag loaded RCD-g-PAN. Where $\Delta W_{1}$ : weight loss of substrate after thermal degradation, $\Delta \quad W_{2}$ : decrease in weight according to the temperature to which they are subjected. 


\section{References}

1. Bhattacharya, A. and Misra, B.N, Grafting: a versatile means to modify polymers techniques, factors and applications. Prog. Polym. Sci.29: 767-814.(2004)

2. Kato, K., Uchida, E., Kang, E.T., Uyama,Y. and Ikada, Y., Polymer surface with graft chains. Prog Polym Sci. 28, 209259(2003).

3. Wandera,,D., Wickramasinghe, S.R. and Husson, S.M., Surface-initiated atom transfer radical polymerization: a new method for preparation of polymeric membrane adsorbers. $J$ Membr Sc. 357, 6-35(2010).

4. Mishra, S., Misra, M., Tripathy, S.S., Nayak, S.K. and Mohanty, A.K., Graft copolymerization of acrylonitrile on chemically modified sisal fibers macromol. Mater. Eng. 286, $107-$ 113(2001)

5. Zhu, J., Bai, Y., Chen, C. and Yang, W., Study of barrier properties of poly(ethylentetraphthalate/acrylonitrile) grafted films. J. Beijing Univ. Chem. Technol. 34, 44-48(2007).

6. Liu, H., Yu, M., Deng, B. , Li, L., Jiang, H. and Li, J., Preirradiation induced emulsion graft polymerization of acrylonitrile onto polyethylene nonwoven fabric. Radiat Phys Chem 81, 9396(2012).

7. Ali, A.M., Mostafa, T.B. and Raafat, A.I., Chemical modification-induced improvement in the electrical characteristics of radiation-functionalized polypropylene sheets. Polymer Int. 59, 557-561(2010). 
8. Mun, S.P., Ku, C.S. and Kim, J.P.., Adsorption of metal and uranyl ions onto amidoximated Pinus densiflora bark. Wood Sci. Technol. 44, 283-299(2010)

9. O'Connell D.W., Birkinshaw C. and O'Dwyer T.F., Heavy metal adsorbents prepared from the modification of cellulose: a review. Bioresour Technol. 99,6709-6724(2008).

10. Mostafa T.B., Chemical modification of polypropylene fibers grafted vinyl imidazole/acrylonitrile copolymer prepared by gamma radiation andits possible use for the removal of some heavy metal ions. J. Appl. Polym. Sci . 111 , 111-18 (2009).

11. Bajpai S.K., Chand, N. and Mary, G., Preparation of poly (acrylonitrile)-grafted silk fibers with antibacterial properties. Fiber Polym. 3,38-345(2010).

12. Jewrajka,K. and Haldar S., Amphiphilic poly(acrylonitrile-coacrylic acid)/silver nanocomposite additives for the preparation of antibiofouling membranes with improved properties. Polym. Composite; 32(11), 1851-1861(2011).

13. Rekharsky M.V. and Inoue Y., Complexation thermodynamics of cyclodextrins. Chem. Rev. 98, 1875-1918(1998) .

14. Ibrahim, N.A., El-S ayed, Z., Fahmy, H.M., Hasabo, A.G.A. and Abo-Shosha, M.H., Perfume finishing of cotton/polyester fabric crosslinked with DMDHEU in presence of softeners. RJTA, 17(4), 58-63(2013).

15. Jaiswala, S., Duffy, B., Jaiswal, A. K, Stobie N. and McHale, P. Enhancement of the antibacterial properties of silver nanoparticles using $\beta$-cyclodextrin as a capping agent Int. $J$. Antimicrob. Agents;36,280-285(2010).

16. Hebeish, A., El-Shafei, A., Sharaf, S. and Zaghloul, S., Novel precursors for green synthesis and application of silver nanoparticles in the realm of cotton finishing. Carbohydr Polym. 84, 605-613(2011).

Egypt. J. Chem. 59, No.5 (2016) 
17. Hebeish, A., El-Shafei, A., Sharaf, S., Zaghloul, S., In situ formation of silver nanoparticles for multifunctional cotton containing cyclodextrin. Carbohydr Polym. 10,442-447(2014)

18. Hebeish, A., El-Shafei, A., Sharaf, S., Zaghloul, S., Development of improved nanosilver-based antibacterial textiles via synthesis of versatile chemically modified cotton fabrics. Carbohydr. Polym. 113, 455-462(2014)

19. Vogel, A. I., “Elementary Practical Inorganic Chemistry”, Part 3, "Quantitative Inorganic Analysis", 2 ${ }^{\text {nd }}$ edition, Longman, London (1975).

20. Rai, M., Yadav, A., Gade, A., Silver nanoparticles as a new generation of antimicrobials. Biotechnol Adv. 27,76-83(2009)

21. Sun, T., Xu, P., Liu, Q., Xue, J. and Xie, W., Graft copolymerization of methacrylic acid onto carboxymethyl chitosan. Eur Polym J.; 39,189-92(2003).

22. Kudryashove, M.A., Mashina, A.I., Tyurind, A.S., Chidichimob, G. and De Filpo. G., Metal-polymer composite films based on polyacrylonitrile and silver nanoparticles. preparation and $\mathrm{p}$ broperties. J Surf Investig- $X-R A, 4$, 437441(2010). 


\title{
تحضير أقمشة قطنية مقاومة للبكتريا عن طريق تخليق جسيمات

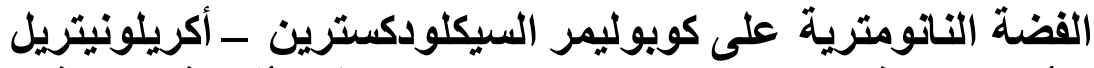 أثثاء عملية البلمرة وشبكها كيميائيا على هذه الأقمشئة القطنية
}

\author{
سلى على حبيش 1، عائشة عبد الحميد حجازى1 ، مروة عبد الهادى 1 و سمر محمد \\ 1 شعبة بحوث الصناعات النسجية ـ قسم التحضير ات و التجهيزات للالياف السليولوزيةـ

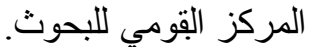

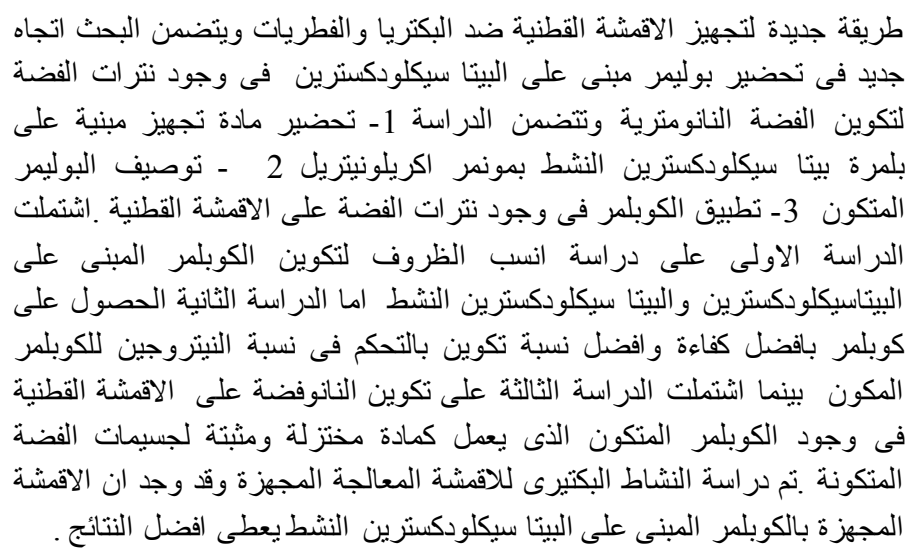


Egypt. J. Chem. 59, No.5 (2016) 